\title{
Was macht den Weg frei bei Rhinitis?
}

\section{Bei leichter persistierender allergischer Rhinitis empfehlen die Leit- linien die Gabe oraler Antihistaminika. Aber hilft, was Jucken und Niesen mindert, auch gegen die nasale Obstruktion?}

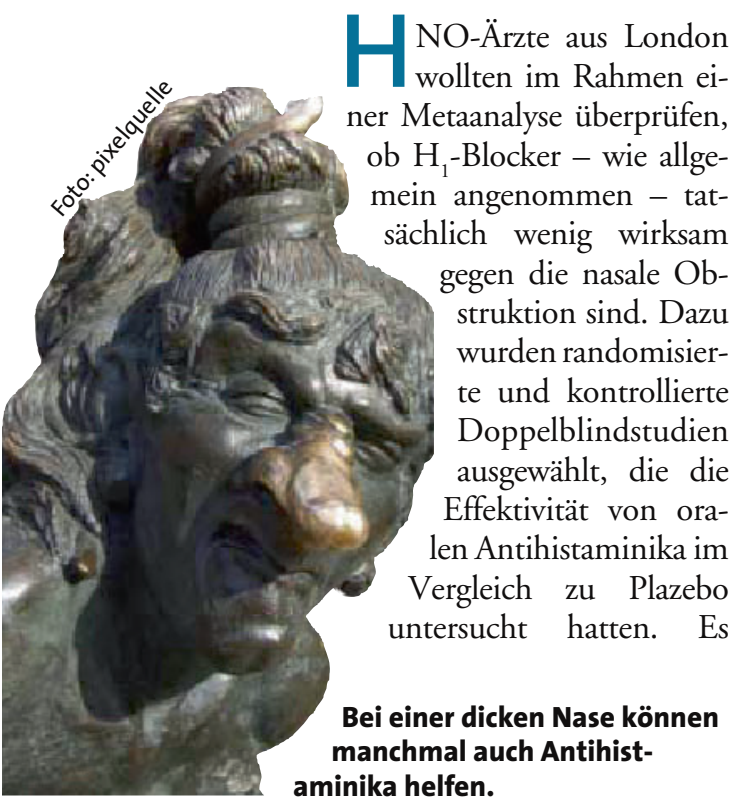

wurden alle Studien in die Analyse einbezogen, in denen die Probanden mindestens 12 Jahre alt gewesen waren, die Diagnose einer persistierenden allergischen Rhinitis durch Pricktest, IgENachweis oder nasalen Provokationstest abgesichert worden war und im Laufe der Untersuchung eine normale Allergenbelastung geherrscht hatte. Zudem mussten die Symptome anhand eines Rhinitisscores quantifiziert worden sein. In der Metaanalyse wurden die Daten der so ausgewählten Studien mit Hilfe einer vierstufigen Skala ausgewertet.

Von 89 ermittelten Studien erfüllten 29 die Einschlusskriterien, von denen aber schließlich nur 7 in die Metaanalyse aufgenommen werden konnten. 13 Studien entfielen alleine deswegen, weil sie eine Übersetzung erfordert hät- ten - möglicherweise ein Schwachpunkt dieser Analyse. Bezüglich der nasalen Obstruktion konnte die Metaanalyse einen signifikanten Effekt der oralen Antihistaminika belegen. Dabei war der Effekt bei Studien, die eine Symptomreduktion aufgrund der Selbstbeurteilung der Patienten belegten, etwas höher als wenn Ärzte oder Pflegepersonal die Symptome einschätzten. Der Effekt lag zwischen $22 \%$ und $31,5 \%$ über dem von Plazebo.

Fazit: Entgegen der landläufigen Auffassung bessern orale Antihistaminika bei persistierender allergischer Rhinitis in einem gewissen Maß auch die nasale Obstruktion. Ob der Effekt für die Lebensqualität der Patienten tatsächlich von Bedeutung ist, müssen weitere Studien zeigen

Hore I et al. Oral antihistamines for the symptom of nasal obstruction in persistent allergic rhinitis - a systematic review of randomized controlled trials. Clin Exp Allergy 2005; 35: 207-12

\section{IDO und IL-10 - zwei wichtige antiallergische Schutzfaktoren}

\author{
Die Mechanismen der immunologischen Toleranzinduktion - sei es \\ auf „natürlichem“ Wege oder durch die spezifische Immuntherapie - \\ sind erst in ihren Ansätzen aufgeklärt. Das Enzym IDO und das Inter- \\ leukin-10 scheinen dabei wichtige Teile des Puzzlespieles zu sein.
}

DO (Indolamin-2,3-dioxygenase) ist ein Tryptophan abbauendes Enzym, das in zahlreiche immunologische Prozesse steuernd eingreift. So induzieren beispielsweise Allergene durch die Aktivierung des hochaffinen IgE-Rezeptors FceRI die IDO-Synthese in Monozyten. Durch den dadurch eingeleiteten Tryptophanabbau mit gleichzeitig ansteigenden Konzentrationen von Abbauprodukten wie Kynurenin werden die TZellproliferation gehemmt und die Apoptose von T-Zellen in Gang gesetzt. Die Aktivierung von FceRI auf Monozyten führt darüber hinaus zu einem Anstieg der Konzentration von Interleukin-10
(IL-10). IL-10 ist ein immunmodulatorisch wirksames Zytokin, das Immunreaktionen herunterreguliert und dadurch vermutlich eine wichtige Rolle in der Toleranzinduktion spielt.

In einer Studie wurden nun die Konzentrationen von IDO und IL-10 im Serum von Patienten mit einer klinisch manifesten saisonalen allergischen Rhinitis $(\mathrm{n}=12)$ sowie von klinisch asymptomatischen, aber sensibilisierten Personen ( $\mathrm{n}=12$; spezifisches IgE gegen Birken- und/oder Gräserpollen $>0,7 \mathrm{kU} / \mathrm{l}$, d.h. CAP-Klasse $\geq 2$ ) gemessen - und zwar während und außerhalb der Pollensaison. Weitere zwölf nicht atopische Probanden dienten als Kontrolle.

Bei den nur sensibilisierten atopischen Personen fanden sich während der Pollensaison eine signifikant höhere Aktivität von IDO sowie erhöhte Konzentrationen von IL-10, während dieser Anstieg bei Rhinitiskranken und den gesunden Probanden ausblieb. Außerhalb der Saison waren die Werte in den drei Gruppen vergleichbar.

Fazit: Bei klinisch asymptomatischer Sensibilisierung steigen bei Allergenkontakt die Serumkonzentrationen von IDO und IL-10 an, während dies bei Gesunden und Allergiekranken nicht der Fall ist. Dem Enzym und dem Zytokin kommen offensichtlich wichtige Funktionen in der Ausbildung einer Allergie zu. $\quad b k$

von Bubnoff $D$ et al. Asymptomatic atopy is associated with increased indoleamine 2,3-dioxygenase activity and interleukin10 production during seasonal allergen exposure. Clin Exp Allergy 2004; 34: 1056-63 